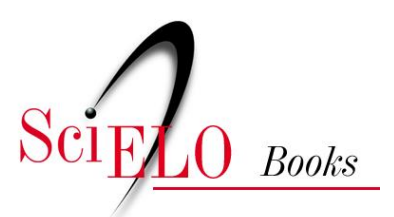

\title{
Seduepb
}

\section{A Personificação Demoníaca de Deus em "Poemas malditos, gozosos e devotos", de Hilda Hilst}

\author{
Paullina Lígia Silva Carvalho
}

\section{SciELO Books / SciELO Livros / SciELO Libros}

CARVALHO, PLS. A Personificação Demoníaca de Deus em "Poemas malditos, gozosos e devotos", de Hilda Hilst. In MAGALHÃES, ACM., et al., orgs. O demoníaco na literatura [online]. Campina Grande: EDUEPB, 2012. pp. 263-276. ISBN 978-85-7879-188-9. Available from SciELO Books <http://books.scielo.org>.

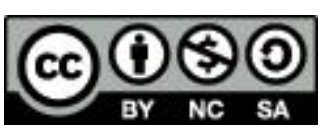

All the contents of this work, except where otherwise noted, is licensed under a Creative Commons Attribution-Non Commercial-ShareAlike 3.0 Unported.

Todo o conteúdo deste trabalho, exceto quando houver ressalva, é publicado sob a licença Creative Commons Atribuição Uso Não Comercial - Partilha nos Mesmos Termos 3.0 Não adaptada.

Todo el contenido de esta obra, excepto donde se indique lo contrario, está bajo licencia de la licencia Creative Commons Reconocimento-NoComercial-CompartirIgual 3.0 Unported. 


\section{A Personificação Demoníaca de Deus em "Poemas malditos, gozosos e devotos", de Hilda Hilst}

Paullina Lígia Silva Carvalho ${ }^{1}$

Eu sou a faca e o talho atroz!

Eu sou o rosto e a bofetada!

Eu sou a roda e a mão crispada,

Eu sou a vítima e o algoz!

(Charles Baudelaire, In: As Flores do Mal).

Ama mas crucifica.

Quase sempre assassino.

É Deus.

(Hilda Hilst, In: Poemas Malditos, Gozosos e Devotos).

\section{Introdução}

As antinomias vida/morte, eternidade/finitude, bem $/ \mathrm{mal}$, assim como, as personificações dessas ideias atreladas as imagens de Deus ou do Demônio, sugerem um tipo de lógica fundante no pensamento mítico e religioso, cujas formas primitivas eram motivadas não pela dualidade do pensamento linear, mas por sincretismos que visavam o sentido de unidade, inseparabilidade, do que seria a compreensão do Todo. Desta maneira, as funções metafóricas da linguagem simbólica e alegórica comum ao mito, à religião e à arte, constroem hermenêuticas capazes de sondar o Inefável, o maravilhoso, harmonizando na consciência

1 Graduada em Letras (UEPB) e Mestranda do Programa de Pós-Graduação em Literatura e Interculturalidade - Universidade Estadual da Paraíba 
humana o que o pensamento objetivante nega por não saber expressar, sem, todavia, conseguir silenciar, encerrar, os questionamentos em torno da experiência transcendente.

Não obstante, as representações feitas por imagens icônicas ou narrativas fabulares vibram o poder do dizer poético capaz de materializar o abstrato e unir os desiguais em um mesmo objeto simbólico: a palavra poética, vista como tentativa de captar o elemento enigmático da vida. $\mathrm{Na}$ obra da autora brasileira Hilda Hilst, opondo-se ao monoteísmo religioso e demais discursos institucionalizantes, a singularidade herética e blasfematória das representações de Deus, assim como a busca pelo Sagrado, posto em diversos textos como um interlocutor privilegiado, revela a heterogeneidade do elemento divino que não é mais estático ou inquestionável como o é a figura de Deus na tradição dogmática mítico-religiosa de diversos segmentos culturais e sistemas de crenças (cristã, judaica, mulçumana).

A palavra poética hilstiana encontra a causa secreta que une os opostos em uma unidade original, não constituindo um subterfúgio, mas formas de desmistificação do sagrado que o pensamento dogmático não é capaz de alçar. No livro Poemas Malditos, Gozosos e devotos (1984), o eu poético hilstiano questiona as motivações dos feitos de um deus-criador, que pode ser compreendido como uma personificação do Deus judaicocristão, cujos traços obscuros revelam uma divindade capaz de (re)unir em si as contradições mais diversas como, por exemplo, a de quem "ama mas crucifica" (HILST, 2004, p. 29). Buscamos, assim, compreender em que medida o elemento sagrado nos poemas de Hilda Hilst se reveste de características vistas como tipicamente diabólicas, de modo que o texto literário passa a desconstruir e rearrumar as formas cristalizadas da imagem de um deus, posto pelo monoteísmo religioso, como Único e imutável, além de inacessível pela sua soberania.

Para um estudo mais aprofundado em torno das personificações do divino no imaginário ocidental, interessa-nos, inicialmente, as considerações de Mielietinski (1987), uma vez que estas nos apontam um caminho para as representatividades míticas dos deuses e heróis-demiurgos dentro de um universo de valores primitivos, cujas imagens reúnem em si características diametralmente opostas, tornando todo personagem mítico, herói-demiurgo, divindade ou ancestral totêmico, um duplo caracterizado pela ambivalência de polos positivos e negativos. Buscamos, neste primeiro momento de articulação teórica, caminhar em encontro com o elemento divino no âmbito das narrativas mítico-bíblicas que fomentaram no Ocidente as ideias de Deus e do Sagrado para, em seguida, 
reencontrar estes a partir das (re)apresentações vistas na experiência mística e poética do livro Poemas Malditos, Gozosos e Devotos, de Hilda Hilst.

\section{As faces do divino e o lugar do sagrado nas narrativas míticas}

Suprimir os paradoxos culturais, seja dentro de um sistema de crenças mítico-religiosas, ou mesmo por meio de práticas políticas, constitui uma ação característica de totalitarismos que visam exercer controle e domínio sobre os modos de vida dos indivíduos, utilizando-se, para tanto, de discursos normativos e institucionalizantes que legalizam determinados modos de ser e exercícios de significação do mundo. A des-institucionalização dos textos, vistos como narrativas sagradas canônicas, a exemplo daqueles que compõem a Bíblia Hebraica e em parte a Bíblia Cristã, é o caminho que nos leva a questionar não apenas as interpretações e significações em torno do mito fundador das religiões, mas também verdades que fomentaram no Ocidente ideias de deus e cultura. Segundo Mielietinski (1987), aquilo que compreendemos como "os eventos dos tempos míticos, as aventuras dos ancestrais totêmicos, heróis culturais, etc., são um original código metafórico através do qual se modela a estrutura do mundo, natural e social". (MIELIETINSKI, 1987, p. 199-200).

Desta maneira, resgatar o elemento divino fora da normatividade dos segmentos religiosos, com o intuito de interpretar para além das "desleituras institucionais", nos reportando a um termo Haroldo Bloom e David Rosenberg (1992), implica em um exercício hermenêutico que vise antes de tudo o alcance do caráter lendário do mito religioso, exigindo, para tanto, uma leitura que se dê a partir de critérios estéticos capazes de nos revelarem a personificação da personagem divina em suas ações dentro das narrativas (des)sacralizadas, de tal forma que possamos nos afastar das interpretações homogeneizantes do caráter e da ação de um deus-criador estático e absoluto, como foi construída a imagem do divino no âmbito do discurso religioso normativo.

Haroldo Bloom e David Rosenberg (1992) nos apontam, ao investigarem as representações de Yahweh nos textos da tradição Javista, quão omitidas foram certas multiplicidades do caráter e da ação de Deus nos textos bíblicos canônicos, revisados e revistos por ideologias religiosas. 
Confrontando estes textos canônicos com as narrativas lendárias escritas, como defende os críticos, por uma autora denominada $J$, sendo esta a responsável pela construção ou reescrituras das arque-histórias bíblicas, somos interpelados antes de tudo pela ambiguidade da persona divina em formas narrativas marcadas pela ironia e pelos confrontos que destronizam o Supremo. Sobre o elemento contraditório suprimido nas narrativas canônicas, Bloom e Rosenberg (1992) nos dizem:

Se a história da religião é o processo de escolhas de formas de adoração a partir de fabulas poéticas, no Ocidente essa história é ainda mais extravagante: ela é adoração, em formas amplamente modificadas e revistas, de um personagem literário extraordinariamente inconstante e estranho, o Yahweh de J. (BLOOM E ROSENBERG, 1992, p.24).

Suprimir o elemento estranho da personagem de Deus nos textos míticos torna-se um trabalho incessante e quase impossível para os interpretes oficiais dos mitos bíblicos, uma vez que o inconstante, o transitório e o diverso parecem mover toda a narrativa, mesmo as canônicas. Atribuindo papéis a certas forças ou personalidades torna-se mais coerente para manutenção de uma estrutura do pensamento linear do que propriamente para significação do divino nas metáforas textuais, em que as imagens da personagem de Deus revelam paroxismos e conflitos latentes. Como exemplo, podemos tomar ação de Deus no livro de Jó, em que Este se move pela perversidade de testar a fidelidade do seu servo até os mais severos castigos gratuitos.

Mielietinski (1992), ao investigar a estrutura do pensamento mítico, afirma que:

A lógica mitológica opera amplamente com oposições binárias de qualidades sensoriais, superando a "continuidade" da percepção do mundo ambiente mediante a distinção dos "quadros" discretos com sinais opostos. Esses contrastes semantizam-se cada vez mais e tornam-se ideológicos, convertendose em meios diversos de expressão das antinomias fundamentais do tipo vida/morte. A superação dessas antinomias através de uma moderação progressiva, i.e, da localização sucessiva de mediadores 
mitológicos (heróis, objetos), que combinam simbolicamente traços dos polos, é uma manifestação nítida da bricolage. (MIELIETINSKI, 1992, p.195-196).

Dentro da unidade do tempo mitológico, cujo campo semântico caracteriza-se pela estabilidade dos sentidos primários e essenciais, o princípio da bricolage, referido por Mielietinski (1992) com base nos estudo do antropólogo Lévi-Strauss, surge como uma espécie de ação unificadora posta como subterfúgio para os conflitos entre dualidades, que não são necessariamente oposições binárias, mas forças que fluem de um só tempo infinito. As representações fantásticas do mundo dentro deste campo semântico estável, que é o tempo mitológico, possibilitam harmonizar os extremos em uma unidade original a partir de um retorno a acontecimentos de um passado mítico fundador. No contexto desse tempo mítico, as figuras dos heróis e deuses demiurgos desempenham uma espécie de papel de sintetizadores/mediadores dos contrários, sendo justamente a ambivalências dessas imagens que "mantém a função simbólica na solução das antinomias fundamentais da própria lógica da narração”. (MIELIETINSKI, 1992, p.208).

De acordo com os estudos de Campbell (2002, p.277), "nas tradições mais antigas, não existe essa separação dualista de poderes e, nós, em nossa forma de pensar, herdamos algo desse dualismo de Bem e Mal, Deus e Diabo, dos Persas". Todavia, o duplo dos heróis e deuses demiurgos não foi totalmente suprimido pelo pensamento e concepções de tempo histórico-cientificizante do Ocidente, considerando que o "pensamento mitológico é por princípio a-histórico, desconhece a heterogeneidade histórica, (portanto) reduz todas as múltiplas mudanças do tempo empírico profano a atos únicos da criação, realizados no tempo mítico sagrado e transcendente." (Idem, p.205).

Neste sentido, o campo semântico do tempo mitológico é um só em todas as culturas, operando-se através de sincretismos que envolvem os paradoxos e antinomias em só fluxo de sentido. Demonismo e cosmismos, assim como o surgimento de divindades demiurgas superiores, tornam-se forças ambivalentes oriundas de um só tempo infinito. (cf. CAMPBELL, 2002, p. 213). Tal é a lógica do tempo mítico fundante nas narrativas bíblicas, de forma que mesmo o modo de compreensão fundada em um tempo linear característico do pensamento ocidental 
não pode negar totalmente as marcas dos sincretismos do pensamento fundado em uma concepção de tempo mítica, visto que mesmo os mitos das tradições monoteístas são regidos por esse fluxo do pensamento que viabiliza o encontro com o Todo.

Questionar a autenticidade do pensamento dualístico é o caminho que nos leva não apenas a uma unidade original baseada em uma concepção mítica do tempo, ou ao mero exercício de correlação dos textos bíblicos hebraicos e do mito cristão com outros modos de representações primitivas, porém ao reconhecimento de diferentes forças ocultas atuando em uma mesma narrativa que nos revela diferentes dimensões do sagrado. Portando-nos, mais uma vez, aos estudos de Campbell (2002) estes nos apontam que há, claramente, mesmo nos textos canônicos hebraicos duas forças ocultas manifestando-se enquanto elemento maravilhoso: uma oriunda de uma divindade sobrenatural transcendente, outra da relação com a natureza em cultos pagãos.

Deste modo, as interpretações de dados elementos simbólicos associados a esta ou aquela divindade não excluem experiência do sagrado atrelado a diferentes forças ocultas, como o sagrado enquanto elemento maravilhoso na natureza, tornado em força demoníaca. A demonização da natureza não exclui a dimensão sagrada que esta assume nem mesmo nas narrativas míticas bíblicas canônicas, Campbell (2002) evidencia

o fato de que em nossa herança europeia cristã tivemos duas mitologias do oculto completamente diferentes para assimilar: a semítica, levantina, de um deus sobrenatural, absolutamente em oposição aos poderes pagãos da natureza, e depois, em contraste com isso, a visão, herdada dos gregos e romanos, de Dionísio, aquela prefiguração do próprio diabo, como uma divindade a ser de algum modo colocada em equilíbrio e em acordo com o deus da luz do clássico mundo apolíneo. (CAMPBELL, 2002, p.279).

Defrontamo-nos, assim, com o limiar de um pensamento fronteiristico, cuja demarcação entre os signos do sagrado e do profano, do divino e do demoníaco, transpõe-se de acordo com as variações das concepções simbólicas de tempo nas narrativas míticas e, consequentemente, 
passíveis das interpretações culturais que estes símbolos assumem dentro do espaço imaginário e social. De acordo com Mielietinski (1992), as concepções míticas não são estáticas, havendo em diferentes culturas, origens, um modo de significar o divino, dizendo-nos:

A mitologia grega é profundamente simbólica, a hindu é até certo ponto alegórica, a persa, esquemática; a grega é realista e evolui do infinito para o finito, enquanto a oriental, idealista, segue em sentido contrário. Para Scheling, o "caráter idealista" oriental (ênfase na essência, na ideia, no ideal) é rematada pelo cristianismo. Acha ele que a matéria da mitologia cristã não é natureza, mas a história, particularmente o maravilhoso na história enquanto esfera da Providência e dos valores morais; aqui o símbolo do universo das ideias não são a natureza e o ser, mas o homem e suas ações, ao invés da divinização do homem a humanização da divindade, tendo-se em vez do panteísmo a hierarquia (os anjos) e uma acentuada oposição entre o bem e o mal (anjo e o demônio). A religião poética é simultaneamente substituída pela religião da revelação. (MIELIETINSKI, 1992, p. 18,19. Grifo nosso.).

Os questionamentos em torno dessa religião da revelação, que interfere as concepções míticas de Deus e do Sagrado no Ocidente, interessam-nos particularmente no momento em que o elemento maravilhoso das histórias fantásticas, vistas nas narrativas míticas hebraicas e cristãs, perde a função alegórica e simbólica de caráter metafórico para tornar-se marcação de um tempo histórico-linear e, a partir de então, servir para fomentações de verdades intransponíveis representadas em divindade absolutas. Neste sentido, a supressão do elemento estético do texto, que deixa de ser fábula poética para tornar-se escritura sagrada, nada mais faz do que engessar os significados polissêmicos do símbolo no mito.

O oculto não atua mais, o maravilhoso já não existe, nenhum deus ou diabo pode agir a partir da formulação do pensamento técnico, tais imagens estão reduzidas aos paradigmas de ideias e interpretações historicizantes dos acontecimentos marcados por uma concepção de tempo linear e dogmas religiosos que, por sua vez, fundem-se nas objetividades do pensamento dualístico, distante e incompatível ao tempo mitológico. 
Desinibir-se dos tabus em torno das narrativas mítico-religiosas, que converteu o elemento simbólico em ideologia da consciência humana, nos conduz ao encontro do poético na narrativa mítica, o elemento poético que chama a presença o divino enquanto o sagrado ausente, mas desvelado na experiência estética da palavra.

Tal exercício, de chamar a presença aquele que antes esteve ausente através do poder do dizer mítico-poético, só pode atuar de acordo com as marcações de um tempo cujas conjugações semânticas sejam capazes de superar as dualidades do pensamento objetivante para adentrar a ambivalência do elemento simbólico, capaz de tornar o sagrado manifesto para além dos cerceamentos das ideias religiosas. A atuação de Deus no âmbito mítico-narrativo supera, portanto, a visão teosófica com base em absolutismos. Deste modo, é que:

\begin{abstract}
(...) o duplo demoníaco ou cômico do herói cultural - pícaro mitológico - também está especificamente correlacionado com o tempo mítico, tendo em vista que este tempo é anterior ao estabelecimento de toda sorte de tabus rigorosos. Até mesmo onde o senhor do céu atua como espírito principal, ele ou se funde com o demiurgo heróicultural, ou permanece uma figura bastante pálida e passiva, uma espécie de deus otiosus, que quase não desempenha qualquer papel nos temas narrativos. (MIELIETINSKI, 1992, p. 224)
\end{abstract}

As imagens do tempo potencializam as concepções de verdade e as formulações do pensamento, atrelando-se, consequentemente, à figura do divino e ao modo como os indivíduos pensam a si mesmo em relação a este Outro. O modo poético, como veremos, configura um sentido diverso, da religião, para ver e relacionar-se com deus, sendo este modo, não obstante, uma forma de interpelar sobre o próprio sentido de vida e morte que cada existência carrega em si.

\title{
O desvelamento da face demoníaca do divino na experiência poética em Poemas Malditos, Gozosos e Devotos, de Hilda Hilst
}


As obscuridades de Deus interessam, particularmente, a poeta Hilda Hilst, em Poemas Malditos, Gozosos e Devotos (1982), ao longo dos 21 poemas que compõem a obra, observamos um tipo de exercício de nomeação e busca do elemento divino. Herético e blasfematório, o eu poético hilstiano assume par si o exercício de pensar e nomear o Deus judaico-cristão, sendo esta uma forma de desvelamento da divindade e do si mesmo do eu lírico. Já na epigrafe introdutória dos textos poéticos, somos interprelados com a seguinte sentença de Simone Weil: "Pensar Deus é apenas uma certa maneira de pensar o mundo".

As múltiplas nomeações da divindade na poética hilstiana condizem, portanto, com a própria multiplicidade dos modos de serem dos indivíduos. Assim, o sádico Deus hilstiano contradiz toda normatividade do discurso dogmático-religioso ao agregar em si características que indicam um estado de humanidade e, portanto, de demonismo-divino, sendo ante a este personagem transversal aos diálogos estabelecidos nos textos poéticos que o eu lírico busca significar-se e construir uma ideia de si e desse Outrodivino (inefável), em forma de palavra-poética que permeia a experiência de um Sagrado dessacralizado. Segundo Marcel Conche (2006):

O sagrado é a categoria específica do religioso como tal, contudo, deixar a religião de lado não significa que não possa haver, no quadro da experiência humana ou do mundo humano algo que tenha uma espécie de afinidade ou de laço com o sagrado. Esse algo parece-me ser o demônico. Empresto essa categoria de Goethe: "o demônico", diz ele, "se manifesta das mais variadas maneiras em toda a natureza, seja ela visível ou invisível." (CONCHE, 2006, p.56).

No primeiro poema, já caracterizado por uma sequência de questionamentos que serão sempre direcionados a figura de um deus, expõe-se uma inversão moral do sentido em torno do sacrifício de Cristo. Vejamos o texto poético:

Pés burilados

Luz-alabastro

Mandou seu filho

Ser trespassado 
Nos pés de carne

Nas mãos de carne

No peito vivo. De carne.

Pés burilados

Fino formão

Dedo alongado agarrando homens.

Galáxias. Corpo de homem?

Não sei. Cuidado.

Vive do grito

De seus animais feridos

Vive do sangue

De poetas, de crianças

E do martírio de homens

Mulheres santas.

(...)

(HILST, 2005, p.13-15)

A plasticidade dos primeiros versos remete-nos, claramente, ao crucificamento do Cristo. A imagem do Cristo-homem transpassado em sua carne, como constantemente ressalta o eu lírico, traz a consciência humana o terror e o medo da informidade de um deus que não se sabe as atrocidades que vela suas intenções obscuras, já que mandou seu filho a crucificação e, não obstante, para consciência poética, ainda sendo um ser que se alimenta "(...) do grito/ De seus animais feridos/Vive de sangue/ De poetas, de crianças// E do martírio de homens/ Mulheres santas.".

Há nesses versos uma clara parodização da moral em torno do mito fundador do cristianismo, além de uma satirização do que seria o amor de um deus-criador por aquilo que não apenas é sua criação, mas seu próprio filho. A ironia da linguagem poética hilstiana, ao renarrar o mito sagrado da salvação no cristianismo, revela a monstruosidade de um Deus do qual somos advertidos a ter "cuidado". Neste poema, há um exercício de releitura e compreensão em torno da imagem do Cristo crucificado, que nos leva ao horror estético ao mesmo tempo em que se estabelece uma sedução, fixação, na carne, na vida, na matéria humana sacrificada, mortificada pelo divino. O caráter irônico desse poema traz a 
angústia de não se saber, ou ter definições, de uma divindade da qual se é servo, filho, criação. Ao fim desse mesmo poema, ante o terror causado por esse Outro-divino-desconhecido, o eu poético declara:

Cantando e dançando, digo:

Meu Deus, por tamanho esquecimento

Desta que sou, fiado da terra, um cisco

Beijo-te pé e artelhos.

(HILST, 2004, p. 15)

Não obstante, é a ausência de Deus que causa alívio, sendo o próprio lugar do desamparo aquele no qual o eu poético sente-se seguro. No poema subsequente, temos algumas características bizarras dessa divindade que, de acordo com a imaginação poética, tem as seguintes formas:

II

Rasteja e espreita

Levita e deleita.

É negro. Com luz de ouro.

É branco e escuro

Tem muito de foice

E furo.

Se tu és vidro

É punho. Estilhaça.

É murro.

Se tu és água.

É tocha. É máquina

Poderosa se tu és rocha.

Um olfato que aspira.

Teu rastro. Um construtor

De finitudes gastas.

É Deus.

Um sedutor nato.

(HILST, 2005, p.17) 
No poema acima, a figura do divino aproxima-se do que seria um lado obscuro do sagrado, no qual o elemento maravilhoso, comumente caracterizado pelo o que é elevado quando associado à imagem de um deus-criador, reveste-se de uma natureza animalesca, cuja perseguição ao homem acaba tornado, consequentemente, em uma divindade demoníaca. Nesses versos há mais do que uma humanização do divino, uma vez que o rebaixamento do sublime ao plano da natureza (carnal-erótico-animal), pertencente à presença de mundo humana, evoca a força do sagrado para além das fronteiras entre deuses e homens, das sublimações do corpo e dos espaços postas pelas mistificações de visões dogmáticas. A experiência do sagrado que extrapola a religião evoca uma dupla mística: a do sublime posto no plano da natureza, sendo esta vista como demoníaca por pertencer à dimensão carnal.

Portanto, a caracterização deste Deus, animalesco e cruel, que logo nos primeiros versos, sabemos que "Rasteja e Espreita/ Levita e Deleita", coloca o divino em confronto com os paradoxos da finitude humana, cuja fonte só pode estar na sua imagem obscura e aterradora para consciência humana. Assim, diz o eu poético: "Se tu és vidro/ É punho. Estilhaça. / É murro." (...) "É Deus um construtor de finitudes gastas". A divindade seria, assim, uma articuladora de ilusões, "É Deus é um sedutor nato", sendo a ilusão primeva posta na própria experiência humana, como diz o eu lírico, em outro poema, sendo preferível a "grande noite negra/ A esta luz irracional da Vida." (p.21). Em uma análise interpretativa sobre a constituição do elemento divino nas tessituras dos textos hilstianos, Anatol Rosenfeld nos diz que:

Os textos, no seu todo, com a audácia da sua linguagem em que o sagrado se reveste de atributos diabólicos e o monstruoso, de cores celestes, são uma celebração ritual levada ao desvario e ao paroxismo; ritual destinado a convocar a plenitude múltipla do homem em toda a sua imanência para, ao mesmo tempo, transcendê-la e fazer vislumbrar "os ares de lá".

Há, portanto, nos poemas hilstianos, um claro desejo de transcendência da finitude humana, que só é possível na rememoração de um tempo mítico capaz reunir deuses e homens, em seus paroxismos, no mesmo espaço, sendo este o espaço simbólico e metafórico da linguagem 
poética. O exercício da imaginação poética transgride as forças religiosas e os discursos harmônicos em torno da personalidade divina, colocandonos diante da monstruosidade de um Deus incomensurável, com o qual se luta confrontando a morte, a finitude, que está em uma consciência de Deus, sabendo-se, não obstante, que só a pulsação poética que torna este Outro existente, uma vez que Ele mesmo reúne em si os conflitos de uma natureza humana. Mais adiante, no poema III, o eu poético nos diz:

\author{
Sou façanha \\ Escuro pulsante \\ Fera doente. \\ À tua semelhança: \\ Homem. \\ (HILST, 2005, p.19)
}

Transportando o Absoluto ao mesmo fluxo de tempo e espaço da obscuridade vista na consciência humana, Hilst nos revela que a animalidade do homem esteve, primeiramente, em Deus, ou nas imagens que este imprime na consciência humana do divino.

\title{
Algumas considerações
}

As discussões realizadas até o presente momento podem até suscitar questões sobre o que a crítica moderna caracterizou como sendo marcas do antropomorfismo de Deus, todavia, o que observamos, com base em uma concepção de tempo anterior, a-histórico, vistas no tempo-espaço semântico dos mitos, é que os modos de representar e compreender os deuses e heróis-demiurgos modeladores culturais não abarcam as caracterizações demarcadas como pertencentes a esta ou aquela força oculta, uma vez que, as narrativas míticas são movidas pelo movimento paradoxal e o elemento divino caracteriza-se por uma imagem ambivalente de um duplo.

O fazer poético hilstiano resgata esse tempo mítico dessacralizado para alcançar um estado transcendente e, assim, harmonizar as dualidades fundadas em uma concepção de tempo linear, superando as sublimações e racionalizações impostas pelos dogmatismos e totalitarismos que institucionalizam a personagem de deus e a experiência do sagrado. 


\section{Referências Bibliográficas}

BLOOM, Harold. ROSENBER G, David. O livro de J. trad. Monique Balbuena. Rio de Janeiro: Imago ed., 1992.

CAMPBELL, Joseph. Mitologia na vida moderna: ensaios selecionados de Joseph Campbell. Trad. Luiz Paulo Guanabara. Rio de Janeiro: Record, 2002.

CONCHE, Marcel. O sagrado e a Solidão. In: O sentido da filosofia. São Paulo: Martins Fontes, 2006.

HILST, Hilda. Poemas Malditos, Gozosos e Devotos. São Paulo: Globo, 2005.

MIELIETINSKI, E. M. A poética do mito. Trad. Paulo Bezerra. Rio de Janeiro: Forense-Universitária, 1987. 